\title{
A reappraisal of the prevalence and clinical importance of left ventricular false tendons in children and adults
}

\author{
JOE MALOUF, WALID GHARZUDDINE, FARID KUTAYLI \\ From the Echocardiography Laboratory, Division of Cardiology, and the Department of Paediatrics, the \\ American University of Beirut Medical Center, Beirut, Lebanon
}

SUMMARY The prevalence and clinical importance of false tendons were studied in 488 consecutive patients referred for echocardiography. Two hundred and eighty three $(58 \%)$ patients had acquired heart disease, $91(19 \%)$ had congenital heart disease, and $114(23 \%)$ had normal hearts. Sixty six patients with normal hearts had innocent systolic murmurs and one had recurrent ventricular tachycardia. The overall prevalence of false tendons was $25 \%$ compared with $1.6 \%$ in a retrospective analysis of 763 cross sectional echocardiograms. When patients with innocent murmurs were excluded from statistical analysis, there was no significant difference in the prevalence of these tendons between children and adults, boys and girls, men and women, or between patients with acquired or congenital heart disease and normal patients. The prevalence of false tendons in patients with dilated left ventricles $(57 \%)$, however, resembled that seen in necropsy studies. The prevalence of false tendons in patients with an innocent systolic murmur was $76 \%$ in children and $40 \%$ in adults, with an overall prevalence of $52 \%$.

False tendons are a common echocardiographic finding of no clinical importance except for their possible role in the genesis of innocent murmurs and ventricular arrhythmias. The echocardiographic detection of false tendons increases considerably when these structures are specifically sought and in conditions that result in left ventricular chamber dilatation.

The echocardiographic features of left ventricular false tendons have been reported, ${ }^{1-3}$ and the reliability of cross sectional echocardiography in the recognition of false tendons has been established. ${ }^{4}$ In a recent morphological study these left ventricular bands were found in $48 \%$ of children and $52 \%$ of adults. ${ }^{5}$ The reported prevalence of false tendons in patients referred for echocardiography, however, has varied widely between $0.4 \%$ to $61 \%$ (Table 1 ). We have re-evaluated the prevalence, location, and clinical importance of false tendons in patients referred for echocardiography and have attempted to explain the major discrepancies between morphological studies and most echocardiographic studies.

Requests for reprints to Dr Joe Malouf, Department of Internal Medicine, King Fahad Hospital, PO Box 22490, Riyadh 11426, Saudi Arabia.

\section{Patients and methods}

Four hundred and eighty eight patients referred for echocardiography over a $2 \frac{1}{2}$ month period were prospectively examined for the presence of false tendons. All echocardiographic examinations were per-

Table 1 Prevalence of false tendons in the reported echocardiographic series

\begin{tabular}{|c|c|c|}
\hline Author & $\begin{array}{l}\text { No of patients } \\
\text { examined }\end{array}$ & $\begin{array}{l}\text { No (\%) with false } \\
\text { tendons }\end{array}$ \\
\hline $\begin{array}{l}\text { Nishimura et } a l^{1} \\
\text { Okamoto et } a l^{7} \\
\text { Vered et } a l^{2} \\
\text { Beattie et } a l^{3} \\
\text { Sethuraman } \\
\text { Gerlis et } a l^{5} \\
\text { Gerlis }{ }^{5} \text { et } a l^{5} \\
\text { Brennert et } a l^{6} \\
\text { Perry et al }\end{array}$ & $\begin{array}{r}1000 \\
132 \\
2079 \\
2004 \\
1012 \\
800 \\
179 \\
100 \\
3847\end{array}$ & $\begin{array}{l}5(0.5) \\
61(46) \\
42(2) \\
84(4) \\
4(0 \cdot 4) \\
3(0 \cdot 4) \\
39(21 \cdot 7) \\
61(61) \\
31(0.8)\end{array}$ \\
\hline
\end{tabular}

*Adult patients only; tpaediatric patients only. 
Table 2 Prevalence of false tendons according to age, sex, and cardiac status in patients without innocent murmurs

\begin{tabular}{|c|c|c|c|}
\hline Category & No of patients & No $(\%)$ with bands & p value $\dagger$ \\
\hline $\begin{array}{l}\text { All ages } \\
\text { Adults } \\
\text { Children } \\
\text { Men } \\
\text { Women } \\
\text { Boys } \\
\text { Girls } \\
\text { Congenital heart disease } \\
\text { Acquired heart disease } \\
\text { Normal hearts } \\
\text { Dilated left ventricle }\end{array}$ & $\begin{array}{r}422 \\
333 \\
89 \\
178 \\
155 \\
54 \\
35 \\
91 \\
283 \\
48 \\
46\end{array}$ & $\begin{array}{l}89(21) \\
69(21) \\
20(22) \\
43(24) \\
26(17) \\
11(20) \\
9(26) \\
16(18) \\
61(21) \\
12(25) \\
26(57)\end{array}$ & $\begin{array}{l}\text { NS } \\
\text { NS } \\
\text { NS } \\
\text { NS } \\
\text { NS } \\
\text { NS } \\
\text { NS } \\
\text { NS } \\
\text { NS } \\
\text { NS } \\
<0.001\end{array}$ \\
\hline
\end{tabular}

«Twenty three patients had aortic regurgitation; 22 patients had a dilated cardiomyopathy; and one patient had mitral regurgitation. †The prevalence of false tendons in each category of patients is compared with the overall prevalence in patients without innocent murmurs.

formed with an Advanced Technology Laboratory (ATL) cross sectional sector scanner with a $3 \cdot 0$ $\mathrm{MHz}$ transducer. Cross sectional studies were performed in the parasternal long and short axis, parasternal apical, apical four chamber, apical two chamber, and right anterior oblique equivalent views. Subcostal views were obtained whenever this was technically feasible. Special transducer angulations (see Results section) were used to obtain better images of the false tendons and their points of insertion. A false tendon was diagnosed if a distinctive linear echo could be seen traversing the left ventricular cavity in one or more echocardiographic sections. We also retrospectively analysed the prevalence of false tendons in 763 consecutive patients referred for echocardiography in the preceding four months.

Both the prospective and retrospective echocardiographic studies were performed and interpreted by two operators (JM and WG); however, false tendons were not specifically searched for when they obtained the echocardiograms included in the retrospective analysis. The levels of attachment of false tendons within the left ventricular cavity were defined as basal, mid, and apical according to previously described criteria. ${ }^{10}$ Care was taken to differentiate false tendons from other echoproducing structures, in particular thickened ventricular trabeculations. ${ }^{4}$

When appropriate Student's $t$ test was used to assess statistical significance.

\section{Results}

CLINICAL CHARACTERISTICS OF PATIENTS

Four hundred and eighty eight patients (378 adults and 110 children below the age of 14 years) were studied prospectively. Their ages ranged from five hours to 84 years. Two hundred and eighty three $(58 \%)$ patients had acquired heart disease, $91(19 \%)$ had congenital heart disease, and 114 patients $(23 \%)$ had no clinical or echocardiographic evidence of heart disease. Sixty six of the patients with normal hearts had an innocent systolic murmur that was grade $1 / 6$ to $3 / 6$ in intensity often with a musical quality, usually heard at the pulmonary area or the left sternal border, but occasionally being loudest at the apex or aortic area. ${ }^{11}$ Two hundred and seventy two $(56 \%)$ patients were male and $216(44 \%)$ patients were female. Sixty six were boys and 44 were girls. One patient was a 27 year old primigravida with a history of palpitation and documented short runs of ventricular tachycardia. The electrocardiogram was normal, and cross sectional echocardiographic examination showed two false tendons but was otherwise normal.

\section{PREVALENCE}

A left ventricular false tendon was found in 123 $(25 \%)$ patients in the prospective study. Ninety six $(78 \%)$ of these patients were $<40$ years old. The prevalence of false tendons in normal patients with and without innocent murmurs was $52 \%$ and $25 \%$

Table 3 Prevalence of false tendons in patients with innocent murmurs

\begin{tabular}{llll}
\hline Category & No of patients & No $(\%)$ with bands & p value \\
\hline All ages & 66 & $34(52)$ & $<0.001$ \\
Adults with IM & 45 & $18(40)$ & 0.01 \\
Children with IM & 21 & $16(76)$ & $<0.001$ \\
\hline
\end{tabular}

*The prevalence of false tendons in each category of patients is compared with the overall prevalence in patients without innocent murmurs.

IM, innocent murmur. 

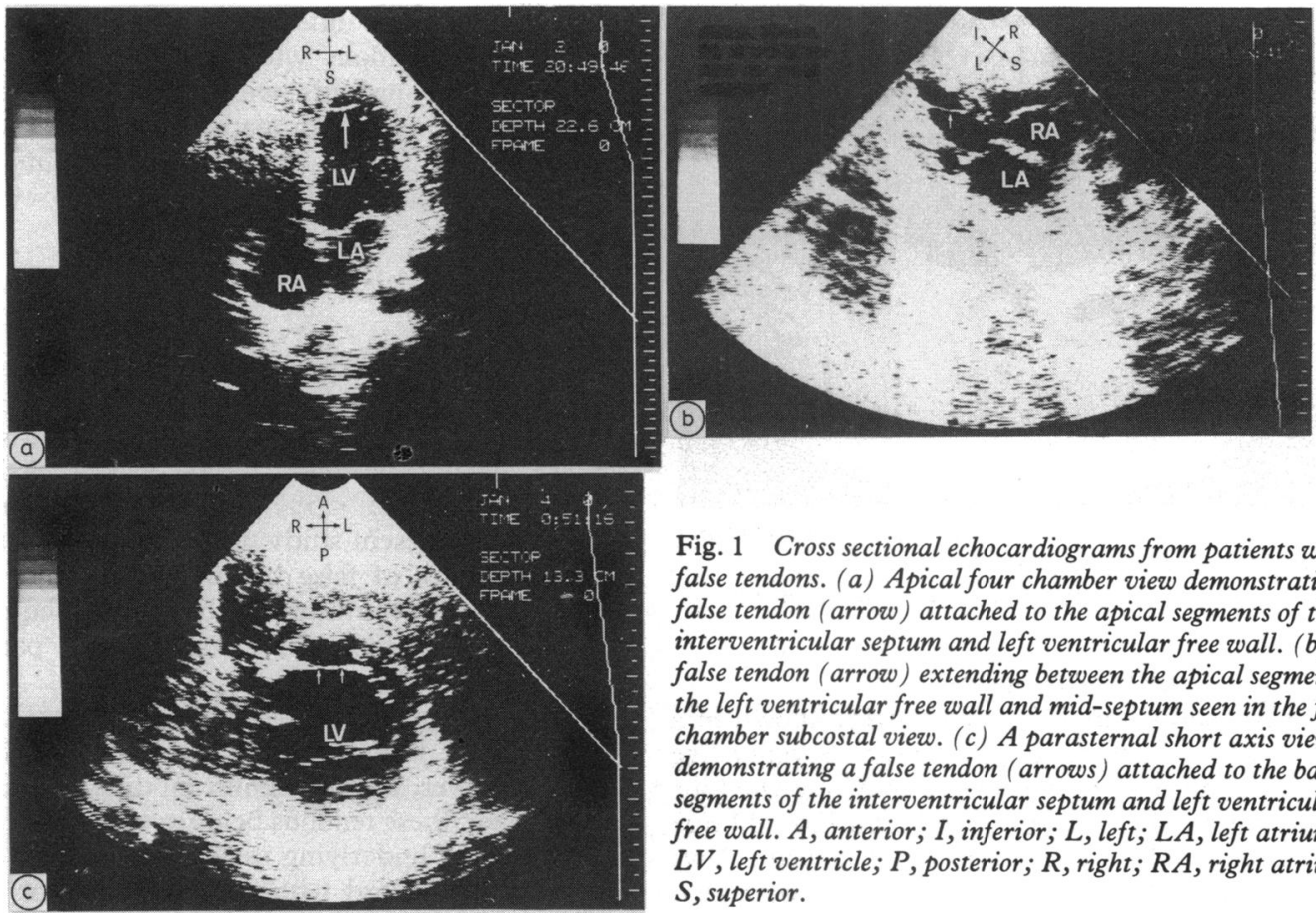

Fig. 1 Cross sectional echocardiograms from patients with false tendons. (a) Apical four chamber view demonstrating a false tendon (arrow) attached to the apical segments of the interventricular septum and left ventricular free wall. (b) $A$ false tendon (arrow) extending between the apical segment of the left ventricular free wall and mid-septum seen in the four chamber subcostal view. (c) A parasternal short axis view demonstrating a false tendon (arrows) attached to the basal segments of the interventricular septum and left ventricular free wall. $A$, anterior; $I$, inferior; $L$, left; $L A$, left atrium; $L V$, left ventricle; $P$, posterior; $R$, right; $R A$, right atrium; $S$, superior.

and without innocent murmurs was $52 \%$ and $25 \%$ respectively (Tables 2 and 3 ). The prevalence of these tendons in patients with acquired and congenital heart disease was $21 \%$ and $18 \%$ respectively (Table 2). In patients with dilated left ventricles (valvar insufficiency, dilated cardiomyopathy) the prevalence of false tendons was $57 \%$ (Table 2). When patients with innocent systolic mumurs were excluded, we found no significant difference in the prevalence of false tendons between children and adults, men and women, boys and girls, acquired and congenital heart disease, or between normal hearts and those with acquired or congenital heart disease (Table 2). Thus the prevalence of false tendons was significantly higher only in those patients with innocent systolic murmurs or dilated left ventricles (Tables 2 and 3).

\section{ECHOCARDIOGRAPHIC ANATOMY OF FALSE TENDONS}

One hundred and twenty three patients had a total of 133 false tendons. A hundred and twenty eight $(96 \%)$ of these tendons extended between the interventricular septum and left ventricular free wall (Fig. 1). The remaining five (4\%) tendons extended longitudinally across one or more adjacent segments of the interventricular septum (Fig. 2). Seventy two per cent of all false tendons connected the apical free wall to the apical segments or mid-segments of the

interventricular septum (Fig. 1a and b). Other sites of attachment included the posteromedial papillary muscle to the interventricular septum $(17(13 \%))$, the mid-segments of the free wall and interventricular septum $(12(9 \%))$, and the basal segments of the interventricular septum and left ventricular free wall $(3(2 \%))$ (Fig. 1c). Ten patients had two false tendons each (Fig. 3), and in four patients branching was evident.

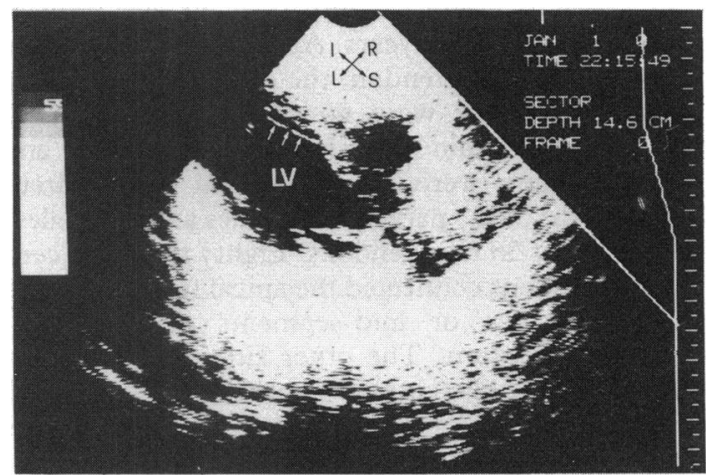

Fig. 2 A longitudinal false tendon (arrows) is seen adjacent to the interventricular septum in the subcostal four chamber view. See Fig. 1 for abbreviations. 


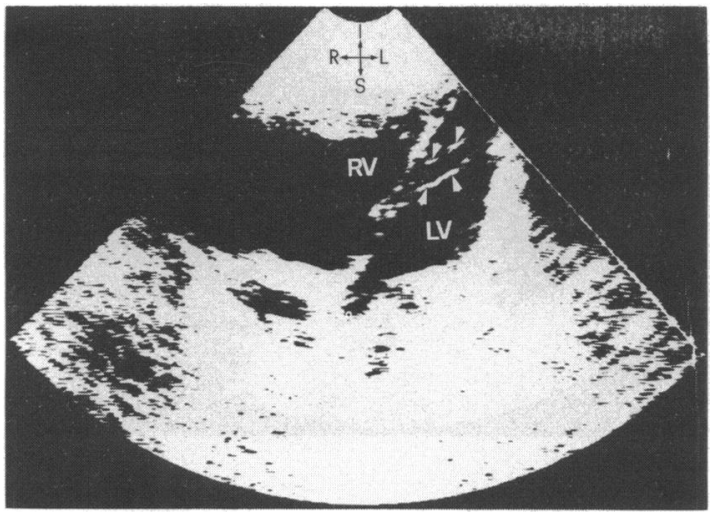

Fig. 3 Apical four chamber view showing two false tendons (arrow heads) traversing the mid-portion of the left ventricle. $R V$, right ventricle; other abbreviations as in Fig. 1.

\section{ECHOCARDIOGRAPHIC VIEWS}

The false tendons in 123 patients were shown in a total of 210 echocardiographic views. Seventy five per cent of all false tendons were shown in the four chamber apical $(33 \%)$, apical right anterior oblique equivalent $(20 \%)$, and parasternal apical views $(22 \%)$. In $67(54 \%)$ patients false tendons were seen in only one echocardiographic section. Often they were only partly displayed in echocardiographic planes requiring special transducer angulations. These usually consisted of counterclockwise rotation of the ultrasound beam from standard echocardiographic planes, in particular the parasternal apical and apical right anterior oblique equivalent views, as well as anterior and posterior tilting of the transducer in the apical and subcostal positions.

\section{INNOCENT SYSTOLIC MURMUR}

The clinical and echocardiographic features of 66 patients (40 males, 26 females) with innocent systolic murmurs were examined. Their ages ranged from four days to 60 years. Apart from the possible presence of a false tendon, the echocardiogram was normal and there were no clinical or laboratory findings to explain the systolic murmur in any patient. There were 45 adults and 21 children. Thirty four ( $52 \%$ ) patients ( 25 males and 9 females) had a total of 36 false tendons. Eighty three per cent of these tendons connected the apical free wall to the apical segments or mid-segments of the interventricular septum. The other sites of attachment were the mid-segments of the left ventricular wall and interventricular septum $(2(5.6 \%))$, the basal segments of the left ventricular free wall and interventricular septum $(1(2.8 \%))$, and the posteromedial papillary muscle and interventricular septum $(2(5 \cdot 6 \%))$. One patient had a longitudinal chord. There was no difference in the level of attachment of false tendons within the left ventricular cavity between patients with and those without innocent murmurs. In patients with innocent murmurs we found false tendons in a significantly higher percentage of children than adults $(p=0.002)$ (Table 3).

\section{Discussion}

Left ventricular bands or false tendons are commonly $\left(\bumpeq 50 \%\right.$ ) found at necropsy. ${ }^{56}$ The prevalence of false tendons in echocardiographic series has varied widely, however, with most studies showing a prevalence of $<5 \%$ (Table 1). Early in the course of the present study we became aware of the high prevalence of false tendons in patients with innocent systolic murmurs (Table 3). Subsequently we specifically sought these structures in patients with innocent murmurs.

The overall prevalence of false tendons excluding patients with innocent murmurs remained high $(21 \%)$, however, with no significant difference in the prevalence of these tendons being noted with respect to age, sex, or underlying cardiac status (Table 2). These results accord with those of a recent morphological study in which there was no significant difference in the prevalence of false tendons between children and adults, boys and girls, or between patients with acquired or congenital heart disease and normal hearts. ${ }^{5}$

The prevalence of false tendons in patients with dilated left ventricles $(57 \%)$ was very close to that observed in necropsy studies. ${ }^{56}$ False tendons are thin string like structures that are stretched out and are possibly better separated from adjacent myocardial structures when the left ventricle dilates, and therefore may become more accessible to the ultrasound beam. The prevalence of false tendons in the retrospective study accords closely with that seen in most echocardiographic series. The echocardiographic yield of false tendons, therefore, appears to be very low unless these structures are specifically searched for. This frequently requires the use of special transducer angulations and the scanning of all possible acoustic windows, only $50 \%$ of false tendons being visualised in a single echocardiographic plane.

Although the accuracy of cross sectional echocardiography in the detection of false tendons has been established, ${ }^{4}$ the echocardiographic differentiation of false tendons from the left interventricular septal border, or from certain pathological intracavitary structures, in particular thickened ventricular trabeculations, can be difficult. ${ }^{4}$ One should therefore, be very cautious in the inter- 
pretation of the echocardiogram when false tendons are sought. This may account for the low prevalence of longitudinal chordae observed in the present report.

There is considerable variation in the distribution of false tendons and their points of attachment in reported echocardiographic series. Vered et al found that $88 \%$ of false tendons were attached to the basal portion of the ventricular septum, ${ }^{2}$ whereas Beattie et al found that only $27 \%$ was attached in this way. ${ }^{3}$ Perry et al found that $97 \%$ of all false tendons extended from a papillary muscle to the ventricular septum, ${ }^{8}$ whereas Brenner et al reported only one patient with a false tendon that was inserted directly into a papillary muscle. ${ }^{6}$ In the present report $13 \%$ of false tendons were inserted directly into a papillary muscle and only $2 \%$ of all tendons were located at the base of the left ventricle or were attached at one end to the basal ventricular septum. The apparent discrepancies in the prevalence, location, and attachments of false tendons in the echocardiographic studies may be attributed to the lack of pathological correlation in most cases, and of a standardised regional analysis of the heart in echocardiographic laboratories.

Although ventricular extrasystoles are common during pregnancy, recurrent bursts of ventricular tachycardia in the absence of underlying heart disease are unusual. ${ }^{12}$ False tendons have been reported to have arrhythmogenic potentials when stretched. ${ }^{813}$ It is therefore possible that conditions resulting in left ventricular chamber dilatation, such as pregnancy, by stretching any existing false tendon may help precipitate a major ventricular arrhythmia.

The association between false tendons and the innocent systolic murmur was emphasised by Roberts. ${ }^{14}$ Although Perry et al confirmed this association in children referred for echocardiography, ${ }^{8}$ the prevalence of false tendons in patients with innocent systolic murmurs is not known. We found that a considerable percentage of children and adults with innocent murmurs had false tendons, suggesting that these features are causally related (Table 3). The true prevalence of false tendons in children and adults with innocent murmurs in the general population remains to be determined, however.

We conclude that false tendons are a very common finding, particularly in patients with innocent systolic murmurs. Further studies are needed to clarify their role in the genesis of innocent murmurs.
We thank Dr Milton Stefadouros for advice and Alice Ashkar for biostatistics.

\section{References}

1 Nishimura T, Kondo M, Umadome H, Shimono Y. Echocardiographic features of false tendons in the left ventricle. $A m$ f Cardiol 1981; 48: 177-83.

2 Vered Z, Meltzer RS, Benjamin P, Motro M, Neufeld HN. Prevalence and significance of false tendons in the left ventricle as determined by echocardiography. $A m \mathcal{F}$ Cardiol 1984; 53: 330-2.

3 Beattie JM, Blomqvist CG, Gaffney FA. Echocardiographic morphology and clinical significance of anomalous chordae tendineae [Abstract]. Circulation 1984; 70 (suppl II): II-335.

4 Keren A, Billingham ME, Popp RL. Echocardiographic recognition and implications of ventricular hypertrophic trabeculations and aberrant bands. Circulation 1984; 70: 836-42.

5 Gerlis LM, Wright HM, Wilson N, Erzengin F, Dickinson DF. Left ventricular bands: a normal anatomical feature. Br Heart f 1984; 52: 641-7.

6 Brenner JI, Baker K, Ringel RE, Berman MA. Echocardiographic evidence of left ventricular bands in infants and children. $\mathcal{F}$ Am Coll Cardiol 1984; 3: 1515-20.

7 Okamoto M, Nagata S, Park YD, et al. Visualization of the false tendon in the left ventricle with echocardiography and its clinical significance. $\mathcal{f}$ Cardiogr 1981; 11: 265-70.

8 Perry LW, Ruckman RN, Shapiro SR, Kuehl KS, Galioto FM, Scott LP. Left ventricular false tendons in children: prevalence as detected by 2-dimensional echocardiography and clinical significance. $\mathrm{Am} \mathcal{f} \mathrm{Car}$ diol 1983; 52: 1264-6.

9 Sethuraman KR, Sriram R, Balachandar J. Left ventricular false tendons: echocardiographic incidence in India and clinical importance. Int $\mathcal{F}$ Cardiol 1984; 6: 385-7.

10 Edwards WD, Tajik AJ, Seward JB. Standardized nomenclature and anatomic basis for regional tomographic analysis of the heart. Mayo Clin Proc 1981; 56: 479-97.

11 Tavel ME. Clinical phonocardiography and external pulse recording. Chicago: Year Book Medical Publishers, 1978: 129.

12 Braunwald E. Heart disease: a textbook of cardiovascular medicine. Philadelphia: WB Saunders, 1980: 1885.

13 Sanders R, Myerburg RJ, Gelband H, Bassett AL. Dissimilar length-tension relations of canine ventricular muscle and false tendons: electrophysiologic alterations accompanying deformation. $\mathcal{O}$ Mol Cell Cardiol 1979; 11: 209-19.

14 Roberts WC. Anomalous left ventricular band: an unemphasized cause of a precordial musical murmur. Am f Cardiol 1969; 23: 735-8. 